O'Donoghue, M. and Cochrane, T.A. (2010) The role of live video capture production in the development of student communication skills. Learning, Media and Technology, in press.

\title{
THE ROLE OF LIVE VIDEO CAPTURE PRODUCTION IN THE DEVELOPMENT OF STUDENT COMMUNICATION SKILLS
}

\begin{abstract}
Civil and natural resources engineering students at the University of Canterbury, New Zealand, take specific courses requiring small group research projects and the presentation of findings to staff and peers. Although one of the aims of these presentations is to assist in the development of the students' communication skills, staff have raised concerns over their effectiveness for this purpose. The Virtual-I Presenter (ViP) software was created to allow students to pre-record and review their presentations through live video capture synchronised to a slide presentation. With no video editing facility available, students were required to repeat recordings which they judged unsatisfactory before submitting their work for staff and peer review.
\end{abstract}

This paper reports on the experience and outcomes from 97 students in two groups using the ViP software. Few students reported the lack of video editing facilities problematic. $80 \%$ of the students using the software reported a positive experience with advantages for the development of their personal communication skills. Other feedback indicates use of the ViP software contributes to self- and peer reflection.

Keywords: video production; live video capture; live to tape recording; oral communication skills; 


\title{
The role of live video capture production in the development of student communication skills
}

\begin{abstract}
Civil and natural resources engineering students at the University of Canterbury, New Zealand, take specific courses requiring small group research projects and the presentation of findings to staff and peers. Although one of the aims of these presentations is to assist in the development of the students' communication skills, staff have raised concerns over their effectiveness for this purpose. The Virtual-I Presenter (ViP) software was created to allow students to pre-record and review their presentations through live video capture synchronised to a slide presentation. With no video editing facility available, students were required to repeat recordings which they judged unsatisfactory before submitting their work for staff and peer review. This paper reports on the experience and outcomes from 97 students in two groups using the ViP software. Few students reported the lack of video editing facilities problematic. $80 \%$ of the students using the software reported a positive experience with advantages for the development of their personal communication skills. Other feedback indicates use of the ViP software contributes to self- and peer reflection.
\end{abstract}

Keywords: video production; live video capture; live to tape recording; oral communication skills;

\section{Issues in student oral presentations}

Students studying Civil and Natural Resources Engineering at the University of Canterbury, New Zealand, have the opportunity to take courses requiring participation in small group engineering projects. Typically, groups of 3-5 students select a theme for investigation which is refined through discussion with the course lecturer. Once a theme has been approved, each group has a few weeks to carry out their investigation and to prepare an 8-10 minute presentation on their activities and findings. The aim of the presentation is to share technical knowledge with the class and provide students with an opportunity to practice and improve their communication skills; this is regarded as an important aspect of professional working life many graduating students will soon experience. Under the current system each group presents their work and findings to staff and their peers in a live lecture-theatre setting. These students have the opportunity to develop their communication skills by way of an oral presentation, the creation of visual materials (usually MS PowerPoint slides), and through a short question and answer session following each presentation - a format similar to many research conference presentations. Though they recognise the importance of communication skills and acknowledge their students need opportunities to develop these, an increasing number of lecturers are raising concerns over the allocation of lecture time set aside for this purpose. In the Hydrology course, for example, at least four one-hour lecture sessions have to be set aside for presentation activities. As Hydrology has three one-hour scheduled weekly lectures, almost two weeks of lecture time need to be set aside for student presentations. In courses with greater student numbers further lecture sessions are required. Setting this volume of time aside for student presentations can be problematic for those lecturers and students who need this time to review or cover new technical material. Time allocation, however, is not the only concern amongst lecturing staff about this activity. Questions 
have also been raised on the how effective students find an 8-10 minute presentation in improving their communication skills.

A number of problems relating to the development of communication skills under the present system were observed during student presentation sessions. Firstly, not all students were actively involved in the oral presentation, nor in the question and answer element that followed. Those students not presenting orally may have made significant contribution to the research investigation or to the creation of the presentation slides or hand outs, but this was not always highlighted. Questions relating to presentation slides rarely picked up points other than minor errors. Secondly, students attending the presentation sessions were focused on their own presentation rather than on those of their peers. Those students yet to present had been observed to engage in silent rehearsal; those students that had presented had 'done their bit' and sometimes displayed a lack of engagement in subsequent presentations. Thirdly, the opportunity for staff or student feedback was limited, usually no more than a few comments with reference to salient points made during the presentation. There was often little-to-no opportunity for the students to respond with their own feedback or commentary or to enter into more detailed discussion should they wish to do so. Fourthly, the opportunity for students to improve their presentation materials or narrative script through preview, rehearsal or peer-commentary was limited. Some groups may have reviewed the duration of their presentation and coordinated the narrative with the slide materials, but the opportunity to experience their own presentation from the audience viewpoint and adapt their materials was often restricted by time and access to lecture rooms and equipment.

That students had not always fully engaged with the presentations of their peers is understandable, not least from the viewpoint that student groups are seeking to make the best of their own presentation slot. Consequently, if the benefits of the sessions set aside for student presentations are limited to relatively few periods in which students are actively engaged in their own presentation or attentive to those of their peers, then the overall effectiveness of the sessions in developing communication skills is questionable. Coupled with time and scheduling concerns discussed previously, consideration as to how students could gain greater benefit from presentation activities which make less demand on class schedules led to the consideration of an alternative approach. One possible solution to these problems was to make use of student produced video.

\section{Educational approaches to video production}

Outside of specialist broadcast and journalism training courses much of the literature on educational or student produced video documents the outcomes or experience of record-edit production and use. Record-edit video production is a process in which an event or scene is recorded using a (video) camera. A number of recorded sequences are then edited together to produce a finished video sequence for presentation or transmission. Record-edit production can make demands on time, particularly where events or scenes are re-recorded a number of times, though there is evidence that students involved in record-edit production develop both communication and technical skills (Buckingham, Grahame, and Sefton-Green 1995). Thornhill, Asensio, and Young $(2002,17)$ use the term "participatory video" to refer to studies "... in which the students themselves can also take control of their own learning by becoming producers". Gauntlett (1998) worked with groups of children aged 7-11 on the production of videos on the 
theme of the environment. He reports the children "...had learned elements of genre and presentation, as well as acquiring a lively awareness of the way in which things could be represented and misrepresented on camera". Frydenberg (2006) found short podcasts produced by the undergraduate students for their peers on a computing course in which they shared "something that they learned during a session" led to increases in downloads and subscriptions, a contrast to the falling number of downloads of his own hour long lecture recordings.

An alternative to record-edit production approaches is live transmission - via satellite, cable, or the internet. Live transmission permits neither editing nor retakes of events or scenes owing to its real-time nature. Live transmission of educational content has been adopted in a number of distance education applications. Thily and O'Donoghue (1995) report their use of a broadcast studio with a live satellite link to train motor vehicle technicians across Europe, an approach permitting real-time interaction between audience and studio via telephone and electronic mail links. Vranch (2005) reports the use of a similar system for surgical training and for other workplace training applications (Vranch and Kingsworth 2002). More recently Robert and Lenz (2009) made use of the same satellite transmission technology used by journalists to report stories during the Iraq War to create a live connection between students on a field trip in Utah and their peers at the University of Central Florida. Though the groups experienced a number of technical difficulties and scheduling problems, the study concludes "the ability to broadcast live from remote areas is only worth the effort if the operation can be configured for two-way interaction".

One approach to video production which adopts aspects of both record-edit and live transmission techniques is live-to-tape recording. In this process, an event or presentation is performed to camera and treated in the same way as a live transmission, but the output is recorded for later transmission and minor modification if required. Should those appearing in front of the camera or the technicians make an error during recording, the option to stop and start again from the beginning may be the only alternative to leaving the error in the recording; in practice, rerecording from a point other than the start is not unusual. A minimal amount of editing from two or more live-to-tape performances is then required to produce a final, error-free programme or video presentation. During this process those appearing in front of the camera and the technicians experience a degree of tension, as with live transmission production, but have the safeguard of a re-recording option should any problems arise. Miller (1996) refers to the "ironic oxymoron of "live-to-tape"" and quotes a network television producer who reported live-to-tape recording "... was a way utilizing the studio facilities more economically". A summary of the respective advantages and disadvantages of live transmission, live-to-tape recording, and recordedit approaches to video production are listed below (Table 1).

Live-to-tape production processes have also been adopted for educational use in the form of recorded or captured lectures. Bell, Cockburn, McKenzie, and Vargo (2001) used captured video of lectures which were indexed to improve access to the different lecture elements. Pincas (2007) describes the use and value of video recordings of lectures within a virtual e-learning community of postgraduate distance education students. These recordings were reduced in duration "by a third or a half" during editing and the content re-ordered "into a more logical structure if necessary". Qvist (2007) reports on the use of live lectures captured in different forms which are "slightly edited" before being made available online as streamed video for postgraduate students 
in problem based learning and science. From the feedback collected from on-campus students he notes "... the feeling of learning (not to be mixed up with actual learning) is an important element for making videos for teaching purposes".

In considering a video production approach suitable to record and distribute presentation materials created by engineering students, live-to-tape recording appeared to offer an efficient approach. The live aspect of recording suggested a comparative presentation experience with the current live group presentation system, yet the recording aspect suggested options for presentation review and improvement which were not currently available.

\section{Developing the Virtual-i Presenter}

Live-to-tape video capture procedures were used as an element in the creation of a student presentation software tool, the Virtual-i Presenter (ViP). The design for the ViP software interface included buttons to start and stop video recording and a window showing the video image being recorded (Figure 1). Alongside the video image, a second window displays a MS PowerPoint slide presentation. As the video recording progresses, students advance their slide presentation by pressing the 'next slide' button. The ViP software records the points at which the slides are advanced and synchronises these with the video recording. At the end of the recording students can review the video recording synchronised with their slide presentation. If the group are not satisfied with any aspect of their presentation they have the opportunity to edit their slide presentation, and/or change their video presentation by re-recording. When each group is satisfied with its slide and video presentation, the captured video, slide presentation and synchronised links are automatically saved to a server for other groups of students and their lecturer to review. A second interface includes options to open, play, pause and stop a presentation (Figure 2). This interface also includes components for collecting feedback from other students and from the lecturer with options to score each presentation on a number of criteria. The scores awarded are saved with any reviewer comments made. Reviewer scores and comments can be accessed by members of the group who created the presentation.

In a similar way to the preparation for the live, oral presentation, the ViP software requires each group of students to prepare both a MS PowerPoint slide presentation and a script or outline of their presentation for video recording. The action of advancing the slide presentation during the live video recording echoes the practice of advancing the slide presentation during a live oral presentation. One feature of the ViP software discussed at the outset was whether groups of students should be provided with tools to edit their video recording. Whilst simple cutting and clipping of video sequences may be easily achieved with the addition of extra software tools, and although simple editing is within the professional practice of live-to-tape production, it was thought the possibility to edit and enhance the video recording could distract students from the key objective of the ViP software, namely to focus students in the development of their personal presentation skills. Recognising that students may experience problems or make errors during video recording, the option to re-record the video presentation from the beginning was made available; this option was considered beneficial, not least because it affords students the opportunity to rehearse and correct their presentation prior to viewing. This latter possibility was seen to move the ViP software away from a direct simulation of a live group presentation.

\section{Results from student use.}


Two trials using the ViP software were carried out. Nineteen students aged 20-21 from a third year Natural Resources Engineering course participated in the initial user trial. The students were divided into ten groups, 9 pairs and one student working alone. Each group was asked to produce a critical review of an Environmental Impact Assessment report of their selection, then to create a written report and an oral presentation based on their review using the ViP software. The guidance for this task specified the presentation should be approximately 6 minutes duration and would contribute up to $5 \%$ of the final grade awarded to each group. The students were given a brief tutorial on how to use the ViP software and were each provided with a copy of the ViP software for installation on their laptop computers. A designated computer room provided access to the ViP software, webcams, microphones, and other peripheral equipment including scanners. Seven of the groups used the resources in the computer room to create their presentations. All of the groups completed the task on time. All students were required to review and score the presentations of their peers. Each presentation was also scored by the lecturer. Scores and comments were collected by the lecturer using the ViP feedback system and an anonymous summary of the feedback for each presentation was forwarded to the students in the respective groups. All of the presentations were created outside of scheduled lecture sessions with one session set aside to review and discuss the students' presentations and their ViP production experiences.

All of the students presented one or more elements of their report on camera. Those students working in pairs sahred the presentation time about equally. Those presentations receiving higher scores and more favorable comments were found to have clearly set out slides and made appropriate use of graphics or photos. Those presentations made by students using their own laptops were often more creative in format, some making use of outdoor backgrounds and others adopting expert interview formats. Fifteen of the nineteen students completed written evaluations. Nine students reported a preference for the ViP software presentation recording and review process to the alternative live, oral, presentation format; seven of these students indicated a preference for a short video presentation format only. Three of the six students expressing a preference for the live presentation format pointed to absence of interaction with the audience during video recording. One student noted:

'Presenting an assignment to a video has a very awkward feeling to it. It is hard to get comfortable. Surely we won't be doing this in our professional career?'

All groups re-recorded their video presentation with a modal average of 5 times requiring a mean average of 1.8 hours to produce. The highest number of re-recordings reported was 14 over a period of 30 minutes from the one student working alone. He added:

"It is short and to the point, you can make a good job of it on video prior to final submission"

Only three students expressed a desire to edit their video or to avoid re-recording from the beginning. Overall the students reported a positive experience producing their presentations with the ViP software. Nine students noted a degree of fun or enjoyment in making the video recordings and using the software. One student commented that it was:

"Easier to do! Video presentation is a LOT less stressful than the live presentation" 
The scores awarded for each presentation by the lecturer closely matched the mean of the student scores awarded with a variation between +0.75 and -0.34 of one mark (see Table 2 ). The overall mean student presentation score was 4.105 (out of 5) compared to the lecturer's overall mean score award of 3.75 .

The second trial involved 78 students working in 18 groups from the final year civil engineering hydrology course. Students in this course are 21-22 years old. Most students presented one or more elements of their report on camera. Those that were not on camera were oberserved or reported helping with the creation and editing of the PowerPoint slides. Most students not on camera also acted as critics and directors for those that were. All of the students were required to review and score the presentations of their peers. Fifty-five students responded to a voluntary survey after completing their presentations. 36 (65\%) of these students reported having no previous experience in making video resources. All of the groups reported re-recording with a modal average of 3 re-recordings. The highest number of single group re-recording reported was between 25 and 30 requiring 2-8 hours to complete. One student from this group reported the best part of this experience was "getting better, improving presentation". Students reported a mean average of 2.5 hours for the video recording with a mean of 3.2 hours to produce the slide presentation. $44(80 \%)$ students commented positively on the use of the ViP software in helping them to develop their presentation skills. Many comments make reference to observing personal idiosyncrasies - eg, "could see instantly how to improve", "made me aware of my non-verbal communication skills", "made me realize I grimace when I'm struggling with a word". 6 students commented on the value of being able to review video and slide presentation materials, eg, "could evaluate both speaking and quality of [slides] at the same time", "review presentation after each run to look for improvements".

Nineteen students (35\%) expressed a preference for the live, oral presentation format with 31 students (56\%) preferring the short ViP video presentation format. Fifteen students $(27 \%)$ reported enjoying watching presentations completed by other groups. Four students reported multiple recordings or "making mistakes and restarting" as the worst aspect of the activity, but only two students suggested editing facilities would improve the ViP software. A further four students suggested a pause feature during recording would be beneficial. Students were asked to evaluate the presentations created by other groups using the ViP evaluations tools in their own time over a one week period. Each student submitted their evaluation scores and comments to the lecturer who compiled and analyzed all evaluations. The lecturer and students' scores for the 18 projects ranged from 9.25 to 12.86 out of 15 .

\section{Discussion and conclusions}

Overall the students' response to the ViP software was very positive. A number of technical difficulties were reported during its use and in the student evaluation feedback, many of which related to its operation on the students' own laptops. The structure and quality of each of the submitted video recordings, viewed alongside the modal averages for re-recordings of 5 and 3 for the different groups before submitting a final recording, suggests most groups produced notes or scripts to guide or structure their presentation, and/or that groups ran through or rehearsed their presentation before attempting to record to video. Only two students reported rehearsal explicitly in the evaluation responses, noting two of their three reported video recordings were rehearsals. This leads to the possibility that students used one or more of their reported video 
recordings for run-through or rehearsal purposes. If this is the case, then the students used the ViP software as a self-evaluation tool, to review their presentation and to collect feedback on those in need of correction; these include those relating to the slide presentation content as well as their respective presentations captured to video. In the case of the larger student groups, more students were involved in the on-camera presentations. With other group members able to offer opinion and point out correction to small errors observed during recording the likelihood of stopping and re-recording is increased. This may explain why the larger groups in the second trial reported a higher modal number of re-recordings than the smaller groups of the first trial, but further work is required to establish the relationship between group size, the number of rerecordings made, and the quality of the finished recording.

One of the aims in producing the ViP software was to allow students the opportunity to develop their personal communication skills. The responses from the two trial groups relating to rerecording and review of their own materials suggests the ViP software has contributed to this aim, perhaps through a more systematic approach than similar preparation activities for a live presentation. The procedures adopted in the use of the ViP software required each student group to review and score the work of their peers. Consequently each student group became active reviewers with a task to complete rather than passive audience for both presentation and content elements of their peers' work. In this respect, the use of the ViP software may be seen to have increased the level of engagement throughout the production, presentation and review aspects of this activity. Unfortunately no direct comparison of the students' experience of presentation using the ViP software with those of students' experiences from previous years using the more traditional presentation format is possible. The lecturer who has experience of working with students using both systems reported his view that '...the ViP presentations are more refined (less errors, more clear) than previous live ones when they did not use ViP'. Further work to examine the students' experience of each of these systems is currently under way.

Live, oral presentation was favoured by 25 of the 74 (34\%) participating students giving feedback. Many of these preferences were underpinned by concerns over a loss of audience interaction or whether producing a video and slide presentation was sufficient preparation for delivering presentations in professional practice. These concerns raise the question as to whether student presentations should be either live and oral, or pre-corded and viewed asynchronously. Student feedback suggests the ViP software is a useful self-evaluation and presentation review tool. One option that addresses the students' concerns would be to use the ViP software during presentation preparation, but to retain a number of sessions for live student presentation. In this way students may benefit by improving their communication skills using the ViP software in preparation for a live delivery to lecturers and their peers, though this approach would still require a number of scheduled lecture sessions to be set aside for student presentations. It may be possible, however, to combine elements of a ViP presentation within a live presentation. Further work to examine how such combinations would work and their demands on the lecture schedule are required to explore this possibility.

One of the concerns expressed during the development of the ViP software was whether the inclusion of video editing tools would distract the students' focus from the presentation of their investigation towards more ambitious video presentations. Only 9 of 74 (12\%) student comments made reference to video editing resources. Such a small number may be due to a lack of 
experience in video production or editing as 70 (95\%) students reported little or no previous video making experience. This feedback suggests the students' focus was on the presentations of their material rather than on enhancing their presentation with video features. However, the pause feature suggested by four students has a connection with live-to-tape recording in professional practice and may assist in minimising students' frustrations experienced during video re-recording. The addition of a pause in recording feature is an option now under further review and development.

Comments made by students in the second trial drew attention to reviewing presentations made by their peers. Fifteen students in this group reported some interest and enjoyment from this activity whilst 18 students found this to be a "boring" activity. The literature on the value of feedback and on peer review suggests this activity to be of significant educational value. Hattie (1999), for example, states "the most powerful single moderator that enhances achievement is feedback". Dochy at al. $(1999,332)$ report “... the main goal of higher education has moved towards supporting students to develop into 'reflective practitioners' who are able to reflect upon their own professional practice". They go on to state "overall, it does appear that self-, peer and co-assessment do improve different aspects of the quality of learning of students". The evidence collected during this study suggests the ViP software may have value as a self-evaluation tool towards the improvement of students communication skills and technical content. The ViP software has provision for the collection of scores and comments by the students' peers and by the lecturer reviewing for each presentation submitted. The presentation and analysis of this data is beyond the scope of this paper, but the possibility to compare the relative scores and comments made by students on their peers' work to those of the lecturer may have some value as a diagnostic tool.

As the recordings produced by the students were digitally captured from their presentations and no physical magnetic video tape medium was used, 'live video capture' may be a more accurate term to describe the process. This process may prove to be of use in other subject areas which face the same problems of scheduling, practice and feedback as those faced by the staff and students in this study and where the adoption of record-edit production procedures are not feasible alternatives.

\section{Acknowledgements}

Thanks to Rob Stowell of the Video Production Unit at UC for his input and comments on professional video practice. The ViP software is available from http://www.virtual-ipresenter.info

\section{References}

Bell, T., Cockburn, A., McKenzie, B., Vargo, J. 2001 Flexible Delivery Damaging to Learning? Lessons From the Canterbury Digital Lectures Project. Proceedings of the World Conference on Educational Multimedia, Hypermedia and Telecommunications, Tampere, Finland, 25-30 Jun 2001, pp117-122.

Buckingham, D., Grahame, J. and Sefton-Green, J. 1995 Making media: Practical production in media education, The English and Media Centre, London. 
Dochy, F., Segers, M. and Sluijsmans, D. 1999 The use of self-, peer and co-assessment in higher education: a review, Studies in Higher Education, Vol 23, number 3, pp331-350.

Frydenberg, M. 1996 Principles and Pedagogy: The two P's of podcasting in the information technology classroom, Proceedings of ISECON, vol 23, Dallas. http://www.screenonline.org.uk/education/glossary.html (accessed October 2009)

Gauntlett, D. 1998 Losing sight of the ball? Children, media and the environment in a video research project, International Broadcasting Symposium, University of Manchester http://www.theory.org.uk/david/videocritical.pdf (accessed October 2009)

Hattie, J. 1999 Influences on student learning, Inaugural lecture, University of Auckland, New Zealand.

http://www.education.auckland.ac.nz/webdav/site/education/shared/hattie/docs/influenceson-student-learning.pdf (accessed October 2009)

Miller, M.J. 1996 Rewind and Search: Conversations with the makers and decision-makers of CBC television drama, McGill-Queens University Press.

Pincas, A. 2007 Videos for live lectures for virtual e-learning: the replication model, Video for education: selected papers from the DIVERSE conferences 2001-2006, volume 1, pp 86-98, ed. Calvery G., Childs, M. and Schnieders, L. Association for Learning Technology, Oxford $U K$

Qvist, P. 2007 Video lectures and PowerPoint presentations, presentation at the $7^{\text {th }}$ DIVERSE international conference on video and video conferencing in education, Hogskolan $\mathrm{i}$ Lillehammer, Lillehammer, Norway.

Robert ,K. and Lenz, A. 2009 Cowboys with cameras: an interactive expedition, British Journal of Educational Technology, v40, no. 1, pp 119-134.

Thily, H. and O'Donoghue, M. 1995 Interactivity Beyond Belief, Interfaces, vol 8, Paris VIII Universite.

Thornhill, S., Asensio, M. and Young, C. 2002 Video streaming: a guide for educational development, JISC Click and Go Project, UMIST, Manchester UK.

Vranch, A. and Kingsworth, A. 2002 Using satellite broadcasts to deliver distance training to the workplace, presentation at the $2^{\text {nd }}$ DIVERSE international conference on video and video conferencing in education, University of Athabasca, Banff, Canada.

Vranch, A. 2005 Integrated satellite TV, video conferencing, and internet video in distance training for surgeons, presentation at the 5th DIVERSE international conference on video and video conferencing in education, Vanderbilt University, USA. 


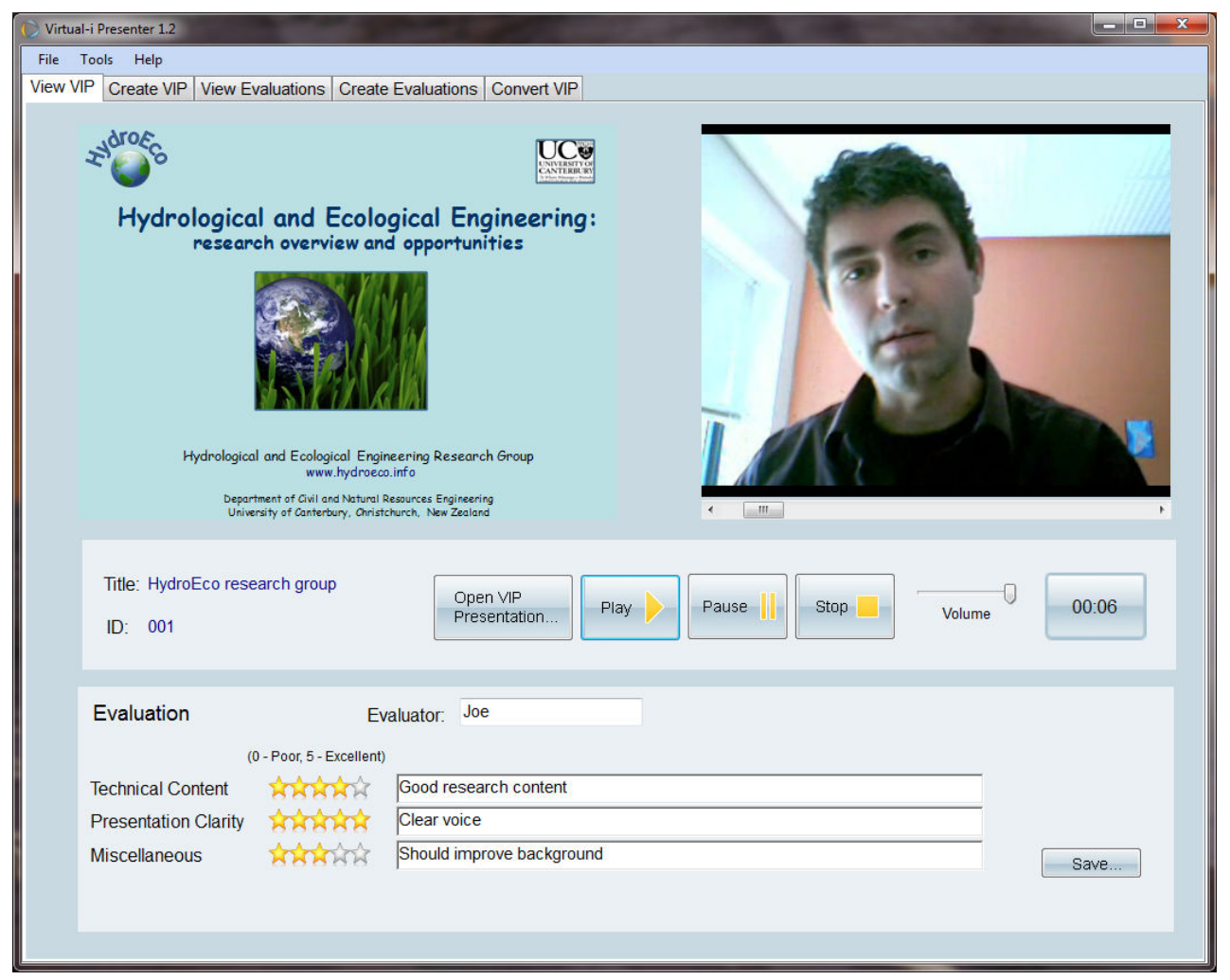

Figure 1: The ViP Presentation and Feedback interface.

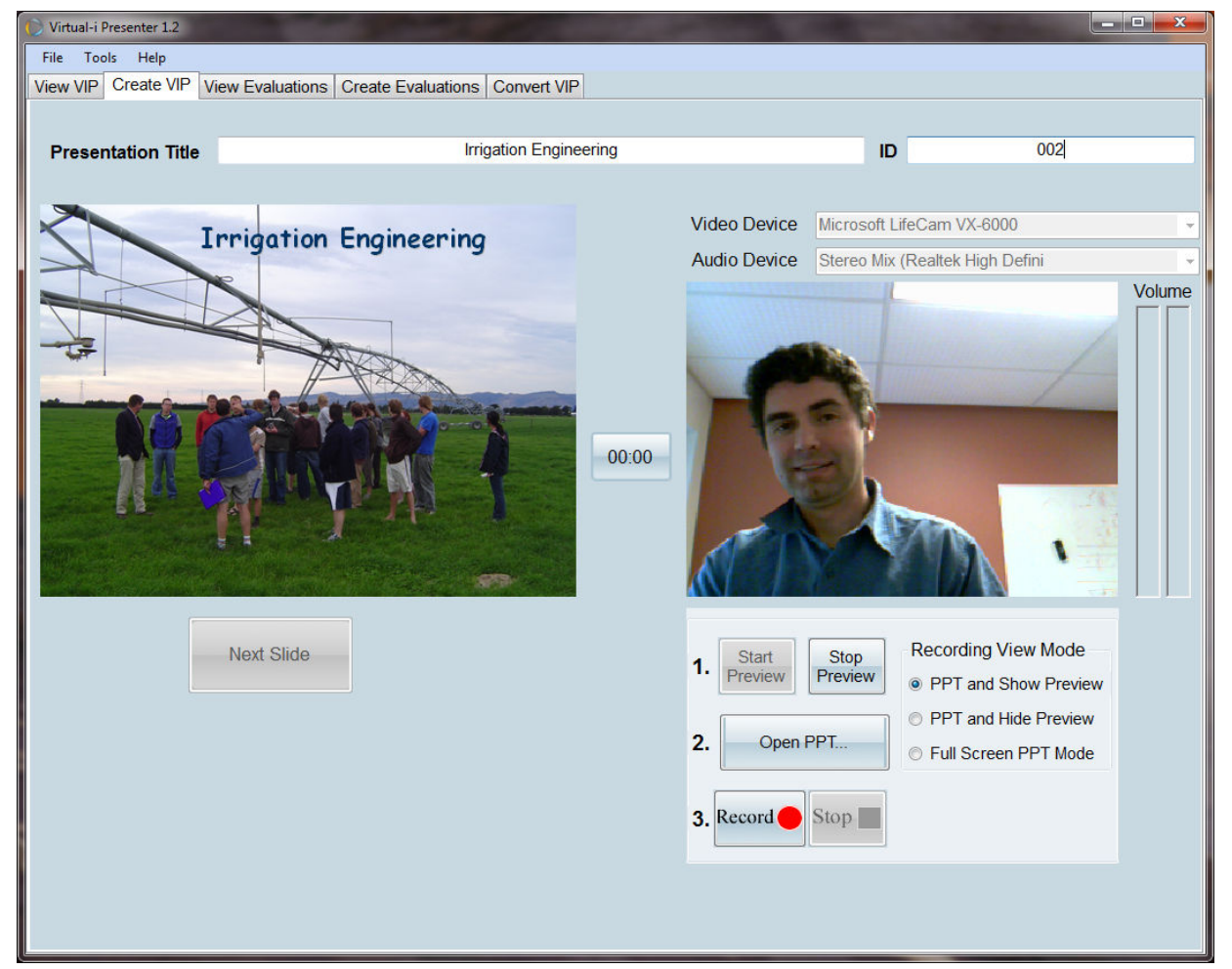

Figure 2: The ViP presentation and video recording interface 


\begin{tabular}{|c|c|c|}
\hline & Production advantages & Production disadvantages \\
\hline Live transmission & $\begin{array}{l}\text { Interaction with remote audience possible; } \\
\text { 'Here and Now'and presence in your own } \\
\text { home aspects; } \\
\text { Little-to-no post production or editing; }\end{array}$ & $\begin{array}{l}\text { Errors made during live presentation cannot be } \\
\text { corrected; } \\
\text { Pressure on talent and production crew to 'get it } \\
\text { right first time'; } \\
\text { Full, professional production crew required; } \\
\text { Costs associated with multi-camera studio, } \\
\text { crew, uplink and transmission may be high; }\end{array}$ \\
\hline Live-to-tape & $\begin{array}{l}\text { Pre-recorded as a live transmission reduces } \\
\text { editing and post-production time and costs; } \\
\text { Significant errors made during recording } \\
\text { can be corrected during re-recording; } \\
\text { Transmission at during off-peak hours or } \\
\text { other distribution possibility to reduce } \\
\text { costs; }\end{array}$ & $\begin{array}{l}\text { Interaction with remote audience not possible; } \\
\text { Pressure on talent and production crew to 'get it } \\
\text { right first time'; } \\
\text { Loss of the 'here and now' live transmission } \\
\text { aspect; } \\
\text { Full, professional production crew required; } \\
\text { Costs associated with multi-camera studio and } \\
\text { crew may be high; }\end{array}$ \\
\hline Record-edit & $\begin{array}{l}\text { Sequences (takes) can recorded multiple } \\
\text { times if required; } \\
\text { One or few production crew required; } \\
\text { Talent and crew under less pressure than } \\
\text { live transmission or live-to-tape; } \\
\text { Single camera production reduces costs; }\end{array}$ & $\begin{array}{l}\text { Interaction with remote audience not possible; } \\
\text { Loss of the 'here and now' live transmission } \\
\text { aspect; } \\
\text { Editing and post-production time and costs may } \\
\text { be high; }\end{array}$ \\
\hline
\end{tabular}

Table 1: Summary of advantages and disadvantages of live, live-to-tape, and record-edit video production approaches.

\begin{tabular}{|c|c|c|c|}
\hline Group & $\begin{array}{c}\text { Student score (mean) } \\
(\mathbf{m a x} 5)\end{array}$ & $\begin{array}{c}\text { Lecturer's score } \\
(\mathbf{m a x} \mathbf{5})\end{array}$ & Difference \\
\hline 1 & 3.89 & 3.25 & +0.64 \\
\hline 2 & 4.00 & 3.25 & +0.75 \\
\hline 3 & 3.91 & 3.50 & +0.41 \\
\hline 4 & 4.00 & 3.75 & +0.25 \\
\hline 5 & 3.83 & 3.75 & +0.08 \\
\hline 6 & 4.22 & 4.00 & +0.22 \\
\hline 7 & 3.94 & 3.50 & +0.44 \\
\hline 8 & 3.91 & 4.25 & -0.34 \\
\hline 9 & 4.27 & 4.50 & -0.23 \\
\hline 10 & 4.18 & 3.75 & +0.43 \\
\hline Overall & 4.105 & 3.75 & +.265 \\
Mean & & & \\
\hline
\end{tabular}

Table 2: Comparison of scores assigned to ViP presentations by students and by the lecturer. The values presented in the lecturer's column for each presentation are the average of the two scores awarded for technical content and presentation clarity. 